\title{
Learning to live with a hand nerve disorder: a constructed grounded theory
}

\author{
Mark Ashwood \\ Christina Jerosch-Herold
}

Lee Shepstone

\begin{abstract}
Study Design: Grounded theory.

Introduction: The broader perspective of health offered by the World Health Organization's Classification of Functioning, Disability and Health (WHO ICF), has had a significant bearing on how we view the measurement of health outcomes after surgical or therapy interventions for peripheral nerve disorders affecting the hand. The value of the patient's perspective is now recognised and outcomes which reflect this are being advocated in the clinical management and support of this population.
\end{abstract}

Purpose of the Study: This qualitative study sought to explore the lived experience of a hand nerve disorder and in particular the impact on body structure/function, activities and participation.

Methods: In depth, one to one interviews with fourteen people with a range of hand nerve disorders were conducted. Constructivist grounded theory methods were used to collect and analyse the data. Patients were also given the option of taking photographs to visually represent what it is like to live with a nerve disorder, to bring with them for discussion during the interview.

Results: The impact of hand nerve disorders forms part of a wider narrative on adaptation. A process of 'struggling' and then 'overcoming' was experienced. This was followed by an interior aspect of adaptation described as 'accepting'. This gave rise to participants 'transforming'; being changed as a result of the journey that they had been on.

Conclusions: This study provides an explanatory theory on the adaptive process following a hand nerve disorder which may inform future patient-therapist interactions.

Level of Evidence: 6 
The World Health Organization's Classification of Functioning, Disability, and Health (WHO ICF) provides a well defined conceptual framework which describes the impact of a health condition on the body, activity and participation while also accounting for contextual factors. The WHO ICF conceptualises the relationship between the components of body functions (physiological functions of body systems) and structure (anatomical body parts), activity (execution of a task or action) and participation (involvement in a life situation) as a consequence of a health condition. This is experienced as bodily impairments, activity limitations and participation restrictions. It also takes into consideration the importance of the environment which make up the physical, social and attitudinal environments in which we live 1 .

This broader perspective of health offered by the ICF has had a significant bearing on how we view the measurement of health outcomes after surgical or therapy interventions for peripheral nerve disorders affecting the hand. There has been a departure from the traditional focus on clinician administered objective tests of physical impairments and a greater appreciation of health status, functioning and well-being; outcomes that are ultimately best judged by patients themselves. Therefore, the value of patients' perspectives of their health is recognised and outcomes which reflect this are being advocated in the clinical management and support of this population.

Qualitative research methodology provides a suitable exploratory approach to understand patient experiences and provides a means from which to obtain a rich and 
important source of information on the impact of health conditions ${ }^{2-4}$. A search for published material on patient experiences of living with a hand nerve disorder, however, identified only four studies, three of which focused solely on carpal and/or cubital tunnel syndrome. Martin explored the health beliefs of individuals receiving conservative treatment for carpal tunnel syndrome, to try and understand why patients had delayed seeking treatment ${ }^{5}$. The impact and expectations for those waiting to have carpal decompression surgery was investigated by Jerosch-Herold et al ${ }^{6}$. Satisfaction with carpal and cubital tunnel decompression surgery was evaluated by Khu et $\mathrm{al}^{7}$. Only one study investigated the consequences and strategies to facilitate adaptation for individuals that had sustained acute nerve trauma to either the median or ulnar nerves but limited to a population who acquired such injury during adolescence ${ }^{8}$.

Despite limited qualitative work on the experience of living with a hand nerve disorder some important findings emerged. Peripheral nerve disorders of the hand cause patients significant burden including sensory-motor disturbance, pain and psychological distress which contribute to activity limitations and participation restrictions. The recovery time from a nerve injury is long, which for some patients was decades, and a full recovery was not possible. Limitations in this work included underreporting of the research methodology and underrepresentation of people with a variety of nerve disorders seen in clinical practice, particularly traumatic nerve disorders. Traumatic nerve disorders are commonly acquired by young adults and the qualitative research does not adequately include the views of this group ${ }^{9}$. The study participants were either children or older adults when they acquired their nerve condition. There was a lack of clarity relating to the conceptualisation of the impact of a 
hand nerve disorder on activity and participation and authors emphasised the need for additional exploratory work ${ }^{6,8}$. To build on this research, further enquiry with people from a much broader range of nerve disorders (compression and trauma), across the lifespan and at different stages of recovery was considered necessary.

2 Purpose of the study

This qualitative study sought to explore the lived experience of a hand nerve disorder and in particular the impact on body structure/function, activities and participation. It investigated the dynamic relationship between these components and sought to understand the personal and environmental factors associated with this condition. The purpose of this paper is to report the methods and findings and to consider the implications for healthcare professionals' management of nerve disorders of the hand.

$3 \quad$ Methods

Qualitative research methodology was used to focus on the lived experience and to ensure patient centeredness ${ }^{2}$. Kathy Charmaz's ${ }^{10}$ constructivist grounded theory methods were modified for this study to generate theory which is grounded in the data collected from its participants ${ }^{11}$. The constructivist approach acknowledges the role of the researcher as integral to the research process throughout and of the construction of the resultant theory ${ }^{12}$. There are three major features of grounded theory which make it distinctive from other forms of qualitative analysis: coding, memo writing, and 
theoretical sampling 11,13. Grounded theorists begin coding as soon as they start to collect data to try to make sense of what is happening. Coding becomes more focused and leads to memo writing. Memos are more analytical and are generated by the constant comparison of new data to existing coding from new participants; they act as a bridge between coding and theory construction ${ }^{14}$. Simultaneous collection and analysis of the data informs the direction of what to collect next and where to find it; referred to as theoretical sampling. This comparative and interpretive process follows the direction of the theory as it emerges ${ }^{15}$.

\section{3:1 $\quad$ Ethics}

The study received ethical approval from the North East York Research Ethics Committee (14/NE/1087/ 28 July 2014) and NHS Research Governance approval (20140RTH07S (99-06-14)/18 August 2014). All participants gave fully informed written consent.

\section{3:2 Patient recruitment and sampling}

The study took place in a secondary care setting between August 2014 and May 2015. Eligible patients were identified through hand therapy record review and included patients currently in treatment as well as those discharged. Patients were eligible for inclusion if they were competent at speaking English, aged 18 years or over and had a diagnosis of either an isolated or combined radial, median or ulnar nerve disorder. 
Sample sizes were not calculated beforehand, as is usual in quantitative research. Instead the optimum sample size is deemed to have been achieved when data saturates or when no new concepts are emerging ${ }^{16}$. To achieve maximum variation in the sample participants with a range of nerve disorder diagnoses as well as sociodemographic characteristics (age, sex, and occupational status) were invited.

\section{3:3 Data collection and analysis}

In depth, one to one semi structured interviews were used to collect data and to give the patient the freedom to discuss their experiences ${ }^{17}$. An interview/topic guide prompted patients to talk about the impact of their disorder on body structures, activities and participation (supplementary material). Patients were also given the option of taking photographs to visually represent what it is like to live with a nerve disorder, to bring with them for discussion during the interview. This visual method was chosen as it has been reported to help foster a sense of participation and a more considered response from the interviewees ${ }^{18-20}$. Leading up to the interview, participants when faced with situations or activities which they deemed to reinforce the impact of their condition, were encouraged to photograph this.

Interviews were recorded using a digital audio recorder, and then transcribed verbatim by the first author. Data collection and analysis occurred simultaneously in keeping with grounded theory methods ${ }^{11}$. The data analysis followed a process of initial, focused and conceptual coding. Initial coding involved naming each line of the written data. Focused coding involved analysis of the most significant or frequent earlier codes. 
Moving from initial to focused coding provided a sense of the main actions and processes which were occurring in the narrative ${ }^{21}$. Conceptual codes were generated by applying the WHO ICF as an analytic scheme to organise and analyse data according to first and second level WHO ICF domains. The ICF was used as a conceptual model, rather than as a classification system to illuminate the interconnectedness between impairments, activities and participation and to allow for communication in a universal language. Therefore, ICF linking rules were not applied as this may have hindered the generation of codes from the data by forcing codes into predetermined categories.

In the absence of a specific core ICF set for hand nerve disorders to guide coding, a modified version presented by Rosén, Jerosch-Herold ${ }^{22}$ was used. Figure 1 below illustrates how the authors have populated the first level ICF categories (in bold) with hypothesised second level ICF categories specific for nerve disorders of the hand (underneath). Using the ICF allowed for comparison across participants and to explore the interactions between the different ICF domains. Memos were written to record this comparative process and to assist with the analysis. This intermediate stage of draft writing bridges the coding of data and the development of conceptual categories. While a topic guide was used there was freedom to follow up new areas of interest as conceptual codes were created. An explanatory theory, grounded in the data was constructed by elevating the data from conceptual codes to conceptual categories. 
Monthly, face to face meetings with all authors, and the random coding of three of the transcripts by the second author ensured the analysis stage involved iterative and rigorous procedures. Additionally, two interim meetings with an advisory panel during the course of the study ensured constant discussion of the credibility of the research process and its findings.

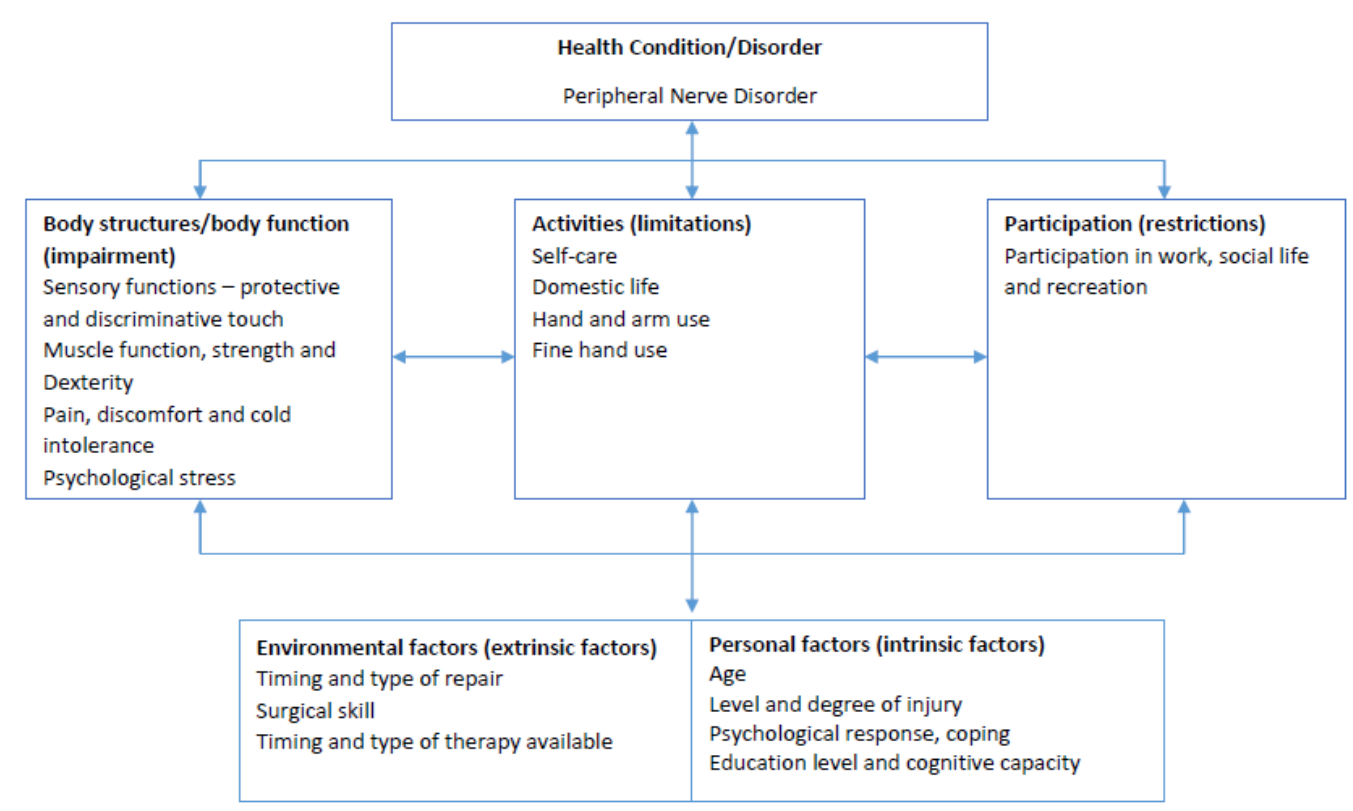

Figure 1: First and second level ICF domains relevant for hand nerve disorders used to guide coding. Illustration from Rosén, Jerosch-Herold ${ }^{22}$, with permission.

$4 \quad$ Results

Fourteen participants were interviewed, three of whom brought photographs with them for discussion. Interviews lasted approximately one hour for each person. There were equal numbers of men and women (Table 1). The age of participants ranged from 25 to 74 years, with a mean age of 55 years. The median time in months from surgery to interview was 34 (range 7 to 108). There was an equal number of traumatic and 
Table 1: Characteristics of study sample

\begin{tabular}{|c|c|c|c|c|c|c|c|}
\hline Participant* & $\begin{array}{c}\text { Age } \\
\text { group } \\
\text { (years) }\end{array}$ & Sex & Condition & $\begin{array}{c}\text { Duration of } \\
\text { symptoms/time } \\
\text { since surgery } \\
\text { (months) }\end{array}$ & $\begin{array}{c}\text { Hand } \\
\text { affected }\end{array}$ & $\begin{array}{l}\text { Type of } \\
\text { surgery }\end{array}$ & Occupational status \\
\hline Peter & $55-59$ & M & Median nerve injury & $34 / 34$ & $\mathrm{D}$ & NR & Metal inspector \\
\hline Claire & $60-64$ & $\mathrm{~F}$ & Median nerve injury & $28 / 28$ & N/D & NR & Volunteer \\
\hline James & $25-29$ & M & Median nerve injury & $35 / 35$ & D & NR & Unemployed mechanic \\
\hline Ray & $70-74$ & $M$ & Ulnar nerve injury & $47 / 47$ & N/D & NR & $\begin{array}{l}\text { Semi-retired stone } \\
\text { mason }\end{array}$ \\
\hline Gary & $25-29$ & $\mathrm{M}$ & Ulnar nerve injury & $25 / 25$ & N/D & NR & Unemployed labourer \\
\hline Richard & $65-69$ & M & Ulnar nerve injury & $7 / 7$ & N/D & NR & Retired farmer \\
\hline Tracey & $25-29$ & $\mathrm{~F}$ & Ulnar nerve injury & $24 / 24$ & D & NG & Sales associate \\
\hline Jeanette & $60-64$ & $\mathrm{~F}$ & Radial nerve injury & $72 / 72$ & $\mathrm{D}$ & $\mathrm{DN}$ & Hairdresser \\
\hline Pat & $55-59$ & M & Radial nerve injury & $44 / 0$ & D & $\mathrm{N} / \mathrm{A}$ & Building manager \\
\hline Joan & $60-64$ & $\mathrm{~F}$ & Radial nerve injury & $52 / 52$ & $\mathrm{D}$ & DN & Office worker \\
\hline Joy & $70-74$ & $\mathrm{~F}$ & $\begin{array}{l}\text { Carpal tunnel } \\
\text { syndrome }\end{array}$ & $108 / 108$ & D & $\mathrm{DN}$ & Carer \\
\hline Lisa & $55-59$ & $\mathrm{~F}$ & $\begin{array}{l}\text { Carpal tunnel } \\
\text { syndrome }\end{array}$ & $39 / 21$ & B & DN & Checkout operative \\
\hline Matthew & $55-59$ & $\mathrm{M}$ & $\begin{array}{l}\text { cubital tunnel } \\
\text { syndrome }\end{array}$ & $58 / 45$ & N/D & $\mathrm{DN}, \mathrm{TN}$ & Retired Lorry driver \\
\hline Pam & $70-74$ & $\mathrm{~F}$ & $\begin{array}{l}\text { Carpal tunnel } \\
\text { syndrome and cubital } \\
\text { tunnel syndrome }\end{array}$ & $60 / 22$ & N/D & $\mathrm{DN}$ & Retired secretary \\
\hline
\end{tabular}

$\mathrm{M}=$ male; $\mathrm{F}$ = female $\mathrm{D}=$ dominant hand; $\mathrm{N} / \mathrm{D}$ non-dominant hand; $\mathrm{B}=$ bilateral; $\mathrm{NR}=$ end to end repair; $\mathrm{NG}=$ nerve graft;

DN=decompression; TN; transposition of ulnar nerve; N/A= not applicable ${ }^{*}$ Pseudonyms have been used 


\section{4:1 Findings}

Initial and focused coding of the data generated hundreds of codes. Using the ICF domains as part of the coding process, facilitated the data to be organised at an individual participant level and across participants for each domain. Memos were written to help deconstruct codes and to understand what constituted them ${ }^{23}$. This process resulted in the collapsing and refinement of codes, reducing the number to 196 conceptual codes. All of the final 196 codes were grouped according to ICF domains to facilitate comparison. Memos were written to collapse the conceptual codes further to create 29 main conceptual codes. These conceptual codes formed four conceptual categories; 1) struggling, 2) overcoming, 3) accepting and 4) transforming. This resulted in the construction of a grounded theory: 'learning to live with a hand nerve disorder'. The process which the participants in this study described was a transformative one. Phrasing each conceptual category in the present tense represents that they are not end-points as participants must learn to adapt over and over again as they experience further nerve recovery or as they encounter new activities or situations which requires them to adapt. A diagrammatic representation of the main conceptual codes and categories that formed the theory is presented (Table 2).

4:2 Learning to live with a hand nerve disorder: a constructed grounded theory

The following account presents the interpretation of the narrative and is supported by extracts from participants' verbatim transcripts (Table 3). Pseudonyms have been used to maintain confidentiality. Participant's occupations and diagnostic information have not been changed as this provided important context to their stories. 
Table 2 A diagrammatic representation of the conceptual codes and categories which contributed to the construction of the grounded theory: learning to live with a hand nerve disorder'

\section{Conceptual codes}

\section{Body Structure and Function}

1. Experiencing positive and negative sensory-motor symptoms and impairments

2. Experiencing pain, discomfort and cold intolerance

3. Experiencing psychological symptoms e.g. PTSD, anxiety and depression

4. Feelings of frustration and anger

5. Emotional response to physical limitations

6. Impact on body image and self-consciousness

7. Further injury as a result of loss of protective sensation

8. Learning to live with sensory-motor symptoms and impairments

9. Self-monitoring for improvement of condition

10. Learning to adapt to sensory-motor deficits

\section{Activity limitation and participation restrictions}

1. Activity limitations with self-care, domestic life and hand/arm use

2. Participation restrictions with work and recreation

3. Struggling with physical demands and pace of work

4. Giving up recreational activities

5. Struggling with bilateral activities

6. Learning to change handedness

7. Things becoming like 'second nature' or adaptation

8. Adaptive strategies to manage activities e.g. extra time, assistive devices, receiving help

9. Adaptive strategies to facilitate participation e.g. phased return, light duties, changing role

10. Work and recreation having therapeutic benefit

\section{Contextual factors}

1. Pre-existing mind-set or personality

2. Understanding of a nerve injury

3. Perception of functional capacity and prognosis

4. Communication from the medical team

5. Rippling effect or the social nature of adaptation

6. Learning to let go of loss

7. Learning to accept the injury

8. Being in the present moment

9. 'Silver linings' or something positive coming from the experience

\section{Conceptual Categories}

\begin{tabular}{llll}
\hline Struggling & Overcoming & Accepting & Transforming
\end{tabular}

\section{Constructed ground theory}

\section{Learning to live with a hand nerve disorder}


Table 3 Extracts from participants' verbatim transcripts are presented to illustrate the development of the conceptual codes and categories which led to the construction of the grounded theory

\begin{tabular}{|c|c|c|c|}
\hline $\begin{array}{l}\text { Conceptual } \\
\text { category }\end{array}$ & Conceptual code & Participant & Extract \\
\hline \multirow[t]{4}{*}{ Struggling } & $\begin{array}{l}\text { Experiencing positive } \\
\text { and negative sensory- } \\
\text { motor symptoms and } \\
\text { impairments }\end{array}$ & James & $\begin{array}{l}\text { "In cold weather my fingertips just go completely cold, as in proper } \\
\text { ice cold but this hand is as warm as anything and the fingers on } \\
\text { this one are really cold". }\end{array}$ \\
\hline & $\begin{array}{l}\text { Struggling with bilateral } \\
\text { activities }\end{array}$ & Pam & $\begin{array}{l}\text { "If you want to cut something on the plate you have to hold the } \\
\text { fork tightly and saw with a knife. That is difficult, so that is another } \\
\text { problem that I do have". }\end{array}$ \\
\hline & $\begin{array}{l}\text { Feelings of frustration } \\
\text { and anger }\end{array}$ & Joy & $\begin{array}{l}\text { "Last year I did this and I did that, now you can't do it and I have } \\
\text { weepy moments, very weepy but not anger more frustration". }\end{array}$ \\
\hline & $\begin{array}{l}\text { Struggling with physical } \\
\text { demands and pace of } \\
\text { work }\end{array}$ & James & $\begin{array}{l}\text { "I've had a couple of jobs in between, one I started at a scrap yard } \\
\text { for I was supposed to have about three months work there but } \\
\text { three days later that was it, I was done. I couldn't keep up and the } \\
\text { bloke said: 'I appreciate that you've had an injury in the wrist but I } \\
\text { do need you a bit quicker'”. }\end{array}$ \\
\hline \multirow[t]{4}{*}{ Overcoming } & $\begin{array}{l}\text { Learning to live with } \\
\text { sensory-motor } \\
\text { symptoms and } \\
\text { impairments }\end{array}$ & Richard & $\begin{array}{l}\text { "I have got this feeling that I always have pins and needles in the } \\
\text { hand. That is something that I am getting used to". }\end{array}$ \\
\hline & $\begin{array}{l}\text { Learning to adapt to } \\
\text { sensory-motor deficits }\end{array}$ & Peter & $\begin{array}{l}\text { "Yes, I've got a good grip, you know, it's there. I tend to have to look } \\
\text { at everything as I'm gripping it to get that surety, rather, whereas } \\
\text { before you would reach out for something without and not really } \\
\text { be looking at it". }\end{array}$ \\
\hline & $\begin{array}{l}\text { Adaptive strategies to } \\
\text { manage activities e.g. } \\
\text { extra time, assistive } \\
\text { devices, receiving help }\end{array}$ & Pam & $\begin{array}{l}\text { "I managed with my right hand quite adequately and you just slow } \\
\text { down what you do. Instead of holding two things in one hand you } \\
\text { just have to go back for the second item". }\end{array}$ \\
\hline & $\begin{array}{l}\text { Learning to adapt to } \\
\text { sensory-motor deficits }\end{array}$ & Joy & $\begin{array}{l}\text { "The cold is very intense, unless it is the summer I always wear a } \\
\text { glove on that hand". }\end{array}$ \\
\hline \multirow[t]{4}{*}{ Accepting } & $\begin{array}{l}\text { Learning to accept the } \\
\text { injury }\end{array}$ & Gary & $\begin{array}{l}\text { "What more can I do about it, there is no point in saying what ifs. } \\
\text { What if that glass had have been somewhere else, would I have } \\
\text { hurt myself? Probably not but then there is nothing that we can do } \\
\text { about that now because it is done, I have a strong will of mind to } \\
\text { see that and to understand that there is nothing that I can do about } \\
\text { that now, what is done is done, get on with it". }\end{array}$ \\
\hline & Learning to let go of loss & Joan & $\begin{array}{l}\text { I don't give up on hope that there will be even more improvement } \\
\text { and if there isn't, there isn't. I mean I am lucky that I have got as far } \\
\text { as I have, absolutely". }\end{array}$ \\
\hline & $\begin{array}{l}\text { Pre-existing mind-set or } \\
\text { personality }\end{array}$ & Peter & $\begin{array}{l}\text { "I am a bit of a cock eyed optimist if you can say that, I do tend to } \\
\text { be optimistic about things, about outcomes, I don't want to accept } \\
\text { grave news unless it really is grave news, there is nothing you can } \\
\text { do about it then. I don't want to accept that something like this can } \\
\text { really make much difference in the end". }\end{array}$ \\
\hline & $\begin{array}{l}\text { Pre-existing mind-set or } \\
\text { personality }\end{array}$ & Tracey & $\begin{array}{l}\text { "Here and there has been barriers, but me as a person, I will find a } \\
\text { way around them or get over them". }\end{array}$ \\
\hline \multirow[t]{5}{*}{ Transforming } & 'Silver linings' or & Tracey & "Before the accident happened I was quite a depressive person. I \\
\hline & $\begin{array}{l}\text { something positive } \\
\text { coming from the } \\
\text { experience }\end{array}$ & & $\begin{array}{l}\text { would always look on the dark side of things. Then I had this } \\
\text { accident and if things had have been even five minutes different I } \\
\text { wouldn't be here and that was a massive wakeup call and I can't be } \\
\text { dealing with depressiveness now". }\end{array}$ \\
\hline & $\begin{array}{l}\text { 'Silver linings' or } \\
\text { something positive } \\
\text { coming from the } \\
\text { experience }\end{array}$ & Joan & $\begin{array}{l}\text { "So I think, having been through what I have been through I have } \\
\text { always been sympathetic, empathetic beforehand but it has made } \\
\text { me more so. More understanding of difficult situations, totally } \\
\text { because I have lived through it, haven't I?" }\end{array}$ \\
\hline & $\begin{array}{l}\text { 'Silver linings' or } \\
\text { something positive } \\
\text { coming from the } \\
\text { experience }\end{array}$ & Matthew & $\begin{array}{l}\text { "So you know as far I think I've no problems I don't worry about } \\
\text { nothing like I used to before there's nothing what will stress me } \\
\text { out and take it and grin and bear it basically what will be, will be as } \\
\text { they say". }\end{array}$ \\
\hline & $\begin{array}{l}\text { 'Silver linings' or } \\
\text { something positive } \\
\text { coming from the } \\
\text { experience }\end{array}$ & Claire & $\begin{array}{l}\text { "I mean I am very grateful for the conclusion that might have } \\
\text { occurred didn't, totally. I have a new outlook on life. I actually } \\
\text { thought I did enjoy life before but I certainly enjoy it now". }\end{array}$ \\
\hline
\end{tabular}




\section{4:3 Struggling}

Many of the participants in this study used the word 'struggle' to describe their early experience of learning to live with sensory-motor symptoms and impairments and the challenges that this presented such as pins and needles, muscle fatigue and hand clumsiness. Participants were vulnerable to injury due to a lack of protective sensation. Pain related to cold intolerance was a central feature. Participants all experienced psychological stress as a direct consequence of their nerve disorder. Symptoms consistent with anxiety, depression and post-traumatic stress disorder were reported.

Richard, a retired farmer, sustained an ulnar nerve injury following an accident using a chainsaw whilst trimming down the branches of a tree. It is interesting that he chose to re-imagine the setting by laying out the chainsaw and protective clothing he was wearing beside the tree he was cutting at the time of the injury and to photograph this and bring to interview (Figure 2). Richard reported that choosing to arrange and photograph the items in this way was representative of his thoughts, as he would often re-imagine the events that led to his accident. 


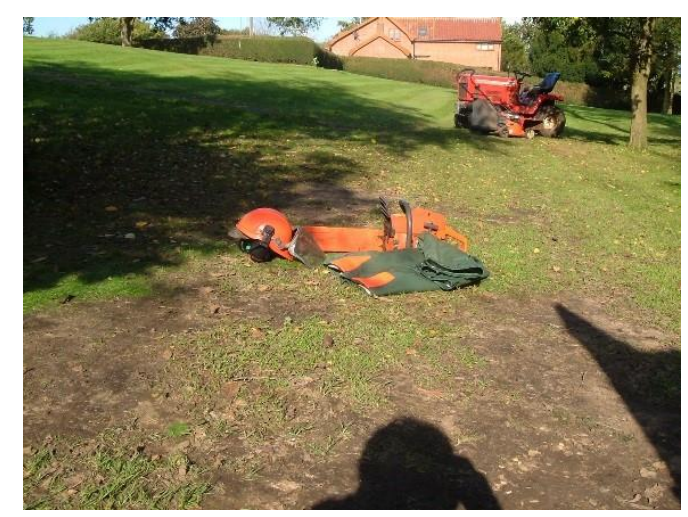

Figure 2 A photograph taken by Richard to re-imagine what happened by laying out the chainsaw and protective clothing he was wearing beside the tree he was cutting at the time of the injury

A similar experience was described by Ray, a semi-retired stonemason, who sustained his injury when falling through a glass greenhouse and severing his ulnar nerve. He said:

"After the accident I would say it is a fairly usual thing for you to re-enact it, you recapitulate in your mind what happened. I think it is part of the mind's way of trying to understand what happened, you know. So I did picture myself doing this thing, almost as though, as if by thinking about it, I could go back and alter it and make a different outcome, but you can't and that is the way the mind works in this case".

The impact of the disorder on body image was important to Richard and he chose to photograph this for discussion during his interview (Figure 3). Photographs of a 'claw' hand deformity associated with an ulnar nerve disorder and the scars from the injury 
were used to express feelings of self-consciousness associated with the cosmetic appearance of the hand/arm.
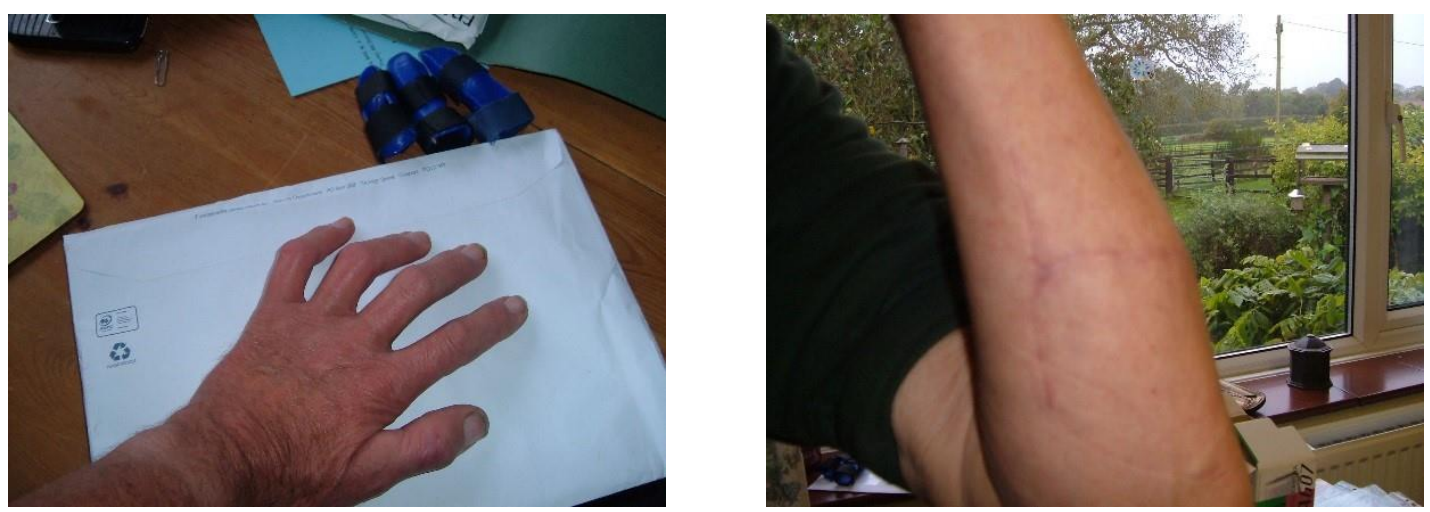

Figure 3 Photographs taken by Richard of his of 'claw' deformity associated with an ulnar nerve disorder and his scars, representing the impact of the disorder on body image

All participants struggled with bilateral activities e.g. cutting food using a knife and fork together, as here participants were forced to use their affected hand and it was more difficult to compensate. For those participants that injured their dominant hand the process of learning to change handedness either temporarily or permanently was stressful. This impacted on their ability to return work, with half of the participants experiencing a change to their occupational status. Those with fast paced or manual jobs were particularly affected. This had a significant impact upon occupational identity and participants expressed that receiving more assistance to learn how to change handedness would have been helpful. 


\section{4:4 Overcoming}

Participants learned to live with impairments, activity limitations and participation restrictions before learning to adapt. Features of this included using vision to compensate for reduced sensation, using the non-affected hand or taking extra time. Using the non-affected hand was easier when performing activities requiring gross motor skills. Activities that required fine sensory-motor skill e.g. handling small coins, were more challenging especially if it had been the dominant hand which was affected. Here compensation with the non-affected hand felt clumsy and could result in things being dropped.

Learning to adapt was more challenging for those who were working and particularly for those with manual jobs. The retired participants in this study benefitted from additional time to explore their environment and to acquire adaptive strategies. The motivation required by participants in learning to adapt was influenced by previous enjoyment of activities, such as sport or recreation or the meaning and value which they attributed to participation in previous roles.

The process of struggling and overcoming was not limited to the individual. Partners, family members and employers were also affected. This phenomenon can be likened to a ripple effect or the incremental and outward consequences created by a single action and highlights the social nature of adaptation (Figure 4). 


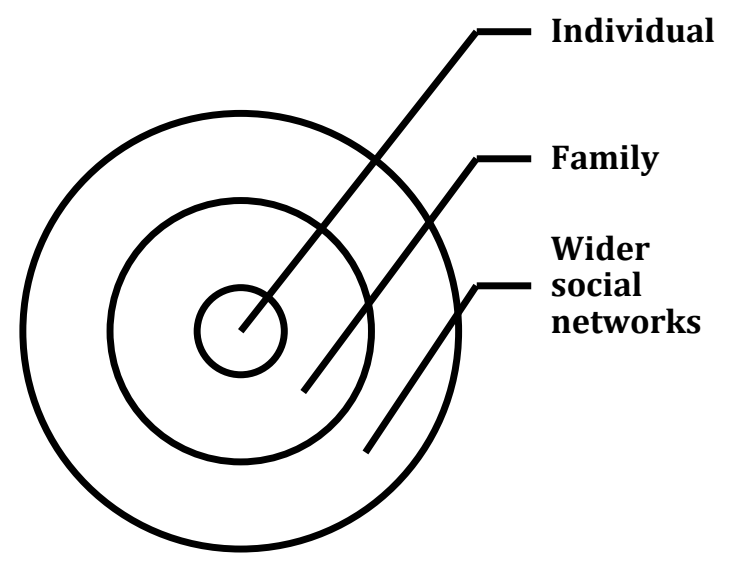

Figure 4 A diagrammatic representation of the 'ripple effect' as a consequence of a hand nerve disorder on the individual, the family and wider social networks

The impact on relationships with partners required them to learn to adapt or else they could fragment and end. Jeanette reported that her relationship with her partner of eleven years became strained due to her dependence on him following her injury. They were not able to adapt to the change in the dynamics of their relationship, which contributed to it ending. She said:

“Because I wasn't 'perfect' any more. I was having to rely on him more. That blew his brains, he couldn't cope with it and we agreed that this wasn't working, so we agreed to part."

For Claire who, following a bilateral injury, was entirely dependent on her husband for personal care, the opposite was true. By learning to give and receive help, their relationship adapted, developed resilience and survived. She reported:

"I guess it brought us a lot closer together I couldn't get embarrassed about anything (laughs). For him I guess it gave him a different understanding of what human beings are about." 
Adaptation also occurred within the family unit; James an unemployed mechanic who sustained a traumatic median nerve injury, highlighted how his young daughter had had to adapt:

"She knows that I have damaged it so she's quite a helpful little girl, she does a lot for me. She remembers and knows that I couldn't do it so she doesn't ask me to do anything like that. It's the same with even doing her coat up, now she still doesn't ask me, she will do it herself or get her mum to do it or even ask her bigger sister. So I suppose yes, she's adjusted to it as well."

Support from employers was also an important aspect of this process. Lisa, a check-out operative with bilateral carpal tunnel syndrome said:

"It was done in the July and by the Christmas I was having so much time off I was earning no money and they were threatening me with the sack and they were really giving me a lot of grief and a lot of bullying."

For James his work colleagues were more sympathetic and supportive; if his own mother could not help, his employer would. Support from healthcare professionals helped participants to understand their condition and their functional prognosis. Joan, a retired office worker with a radial nerve injury, expressed the importance of this when talking about the therapy she received saying: 
"For the long term support it was the hand therapy, it was extremely good and it was quite hard after quite a while to stop going because it was just quite nice to get the reassurance of progress, it's getting better."

Conversely poor communication or being given unrealistic advice from the medical team could lead to anxiety and low mood. Peter, a metal inspector who sustained a major hand injury after a circular saw accident remarked:

"They come in and they open my notes and they say: 'It was quite horrific; you are lucky you didn't lose your arm'. And then surprisingly you get used to people saying that but when you first hear it is quite a shock."

Tracey, who had acquired an ulnar nerve injury, from a glass laceration, highlights how impractical and unhelpful some of this advice was for her:

"I had to bath both my children; things that the doctors were saying that you can't do... I was on my own and I had to do something. I couldn't just leave him until my partner got home. So you do have to get them dressed, feed them and do everything that you are not supposed to do." 


\section{4:5 Accepting}

Learning to live with and adapt to physical and functional impairments led to an internal process of psychological adaptation or 'acceptance'. Personality type and preexisting coping strategies influenced how the participants responded to the impact of the disorder. Over time participants learned to live with and accept their condition. Here Peter reflected:

"These are the things I've got to live with rather than think there is going to be a cure. There is not going to be a 100\% recovery as such".

Gary, who sustained his injury whilst working in a glass factory expressed that this process was character building:

"It is who I am, it is part of me and I just get on with it. I have hurt myself, I've learned from it, people make mistakes; we gather scars you try and learn from these things."

For Claire, who had acquired a median nerve injury from deliberate self- harm, acceptance involved being able to let go of the past and being in the present moment: 
"I suppose again it is acceptance, isn't it? There is nothing you can do as you can't turn the clock back. I had to accept that this was the new reality."

Joy, a carer, had surgery for acute onset of carpal tunnel syndrome following a fall down the stairs. She brought this photograph with her showing the scar on her wrist (Figure 5). Joy sustained her injury ten years prior and over time had learned how to adapt to her symptoms and functional difficulties which she described as being part of her. While she had residual sensory-motor symptoms she expressed that she was still experiencing nerve recovery. Joy was accepting of her present state and yet hopeful for further improvement. Joy communicated this through the photograph of her surgical scar. The scar is faded but serves as a reminder of what happened and that while she has learned to adapt to and live with a hand nerve disorder, she still experiences the impact of the condition with ongoing pain and sensory symptoms.

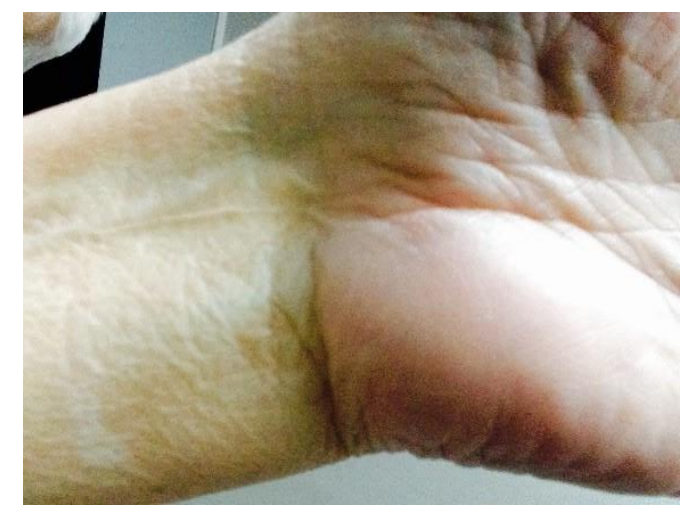

Figure 5: Photograph taken by Joy of a faded surgical scar from her surgery over ten years prior 
4:6 Transforming

Participants described a transformative experience as a result of the journey that they had been on. Tracey used the proverb by John Milton 25: 'every cloud has a silver lining' to describe the phenomena of something positive stemming from this negative experience. While this experience varied amongst participants, collectively it became a metaphor for optimism and hope for the future.

"It is a bit of a silver-lining really for me...I hate the idea that I have missed an opportunity somewhere or that time with my kids is being wasted or that I am doing something that I shouldn't. I just look at things so differently now, which is good."

Peter described how his accident had helped him with developing resilience and becoming more assertive:

"Maybe in certain respects a stronger person in character. Being able to not worry about what other people think. To be able to speak out"

Matthew, a retired lorry driver with cubital tunnel syndrome reflected on having greater self-awareness and desire to look after his well-being: 
"I think I'm more relaxed than I was prior to. I think I was more stressed up while I was working and now I've had this done it's almost a wakeup call to say: 'well, slow down, ease up',"

For Claire the process fostered a greater sense of compassion and empathy:

"I think that it has given me a greater understanding of what other people go through; if they need to talk, to give them time and to not say to them to 'pull yourself together.' There has been a lot of positivity that has come out of the negative action."

'Milton's clouds' creates an image of turbulent storms, this motif is built upon by Richard choosing to photograph a rainbow that appeared over his land after a rainstorm. Richard chose to include these photographs to represent gratitude for all that was in his life and for a return to calmness and peace (Figure 6).
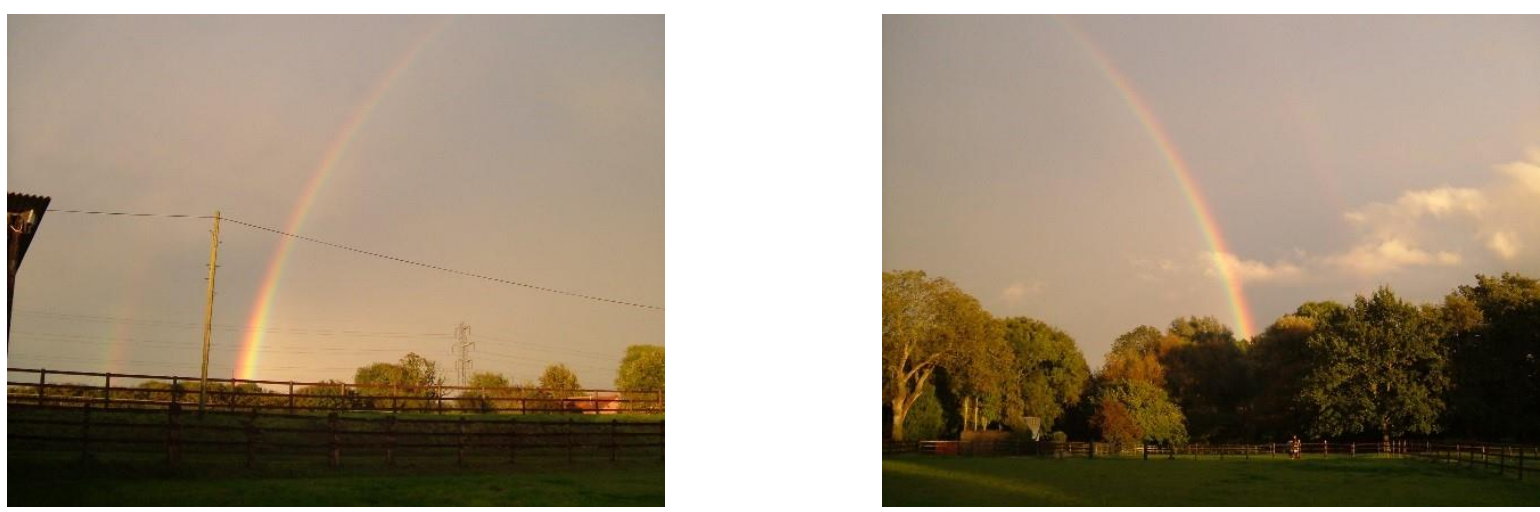

Figure 6: Photographs of a rainbow over Richard's land after a rainstorm signalling a return to calmness and peace 
This study sought to explore the lived experience of a peripheral nerve disorder and in particular the impact on body function, activity and participation. Early into the coding process it was apparent that this impact forms part of a wider narrative on adaptation. A process of 'struggling' and then 'overcoming' was experienced. The word struggling was used by participants and related to when they were experiencing sensory-motor impairments. Injury as a result of lack of protective sensation and pain related to cold intolerance were also experienced. Psychological stress was a significant clinical feature with symptoms of anxiety, depression and post-traumatic stress disorder described by many participants.

A feature of struggling is that participants are trying to make sense of what has happened and how this has affected their daily lives. Struggling is also a process of trying to participate in life, learning to live with symptoms and using these experiences to become more independent. This learning process leads to people 'overcoming'. Here a range of effective adaptive strategies were used. The meaning that participants attached to activities was a motivating factor.

While overcoming is a largely physical/functional process this was also accompanied by an interior aspect of adaptation described as 'accepting'. This involved learning to let go of loss and being in the present moment, irrespective of whether further nerve recovery was possible. This gave rise to participants 'transforming'; being changed as a result of the journey that they had been on. 
Participants described sensory-motor and proprioceptive impairments, pain and cold intolerance consistent with other qualitative studies with this population ${ }^{5-8}$. Chemnitz explored the psychological impact of a nerve disorder and recommended the need for ongoing psychological screening ${ }^{8}$. Our study confirms this and that this also be considered for people with chronic nerve compression disorders. As patients begin to experience nerve recovery relearning how to perform activities of daily living can be stressful. Skill acquisition and relearning is an incremental process and occurs over a long period of time, therefore patients are vulnerable psychologically and the clinical team should monitor this through all stages of nerve recovery.

It became evident that participants begin to compensate quickly following a nerve disorder which made it difficult to assess the impact of the condition on activity. Activities which required bilateral hand function were harder to adapt to as participants were forced to use their affected hand. This created a significant barrier to participation in recreational activities and work. Many of the participants learned to change handedness either temporarily or permanently, which was both stressful and challenging. There was a desire for more help from hand therapists through this process. The significance of hand dominance and bilateral activities has not been discussed by the authors of other qualitative studies reporting the experience of peripheral nerve disorder and this novel finding has clinical implications. Having dedicated therapy time to learn how to change handedness such as that proposed by Yancosek, Calderhead ${ }^{26}$, as well as opportunities for recreational and vocational rehabilitation may assist with this transition. 
The experiences of the participants in this study revealed that the impact of a hand nerve disorder forms part of a wider narrative on the process of adaptation. Adaptation following a hand nerve disorder is not a new concept and adaptive strategies have been described by authors of the other qualitative studies with this population ${ }^{5-8}$. Hope refers to 'occupational adaptation' a model derived from occupational therapy theory. Here participation in meaningful activities or 'occupations' provides a vehicle for adaptation as well as a desire for adaptation to occur ${ }^{27}$. Participation in meaningful activity was a key feature of the 'struggling' experience of participants in this study. It was the experience of and often the mistakes made which facilitated 'overcoming'. The Occupational Adaption model, however, accounts primarily for an individual's response to internal and external factors and has been observed by others to not sufficiently capture the social aspects of adaptation which was a prominent feature of this study ${ }^{28}$.

Charmaz also describes an adaptive process observed with people with chronic conditions which takes into account the social context of adaptation. This firstly centres around the individual but also takes into account the views of significant others and the interactions between them ${ }^{29}$. It follows three major stages: (1) the experience of illness (2) weighing up losses and gains and the revision of goals, and (3) surrendering to the sick self by relinquishing control over illness. There are similarities in the process and the experiences of the participants in her study with our study. The most obvious difference is that the participants in her study were becoming progressively ill and less reliant on their bodies, whereas the participants in our study were getting better as they experience nerve recovery. 
The passage of time and uncertainty pertaining to functional prognosis is a shared characteristic of people with both progressive chronic conditions and those with hand nerve disorders. The former experience physical and functional difficulties over a period of time requiring them to adapt. The latter experience the slow nature of nerve recovery, over many years and not knowing how much recovery is possible. Both individuals with chronic conditions as described by Charmaz and those with a hand nerve disorder learn to adapt over many times as their conditions change either by progression of their illness (Charmaz) or functional gains from nerve recovery.

Acceptance has also been described in the literature as integral to adaptation following a major hand injury ${ }^{30}$. It has been suggested that acceptance occurs commonly when patients plateau in their rehabilitation and thus patients learn to live with what they have left ${ }^{31}$. While the word 'acceptance' suggests an end point this study offers 'accepting' as a process which is still occurring. Participants in this study were still experiencing nerve recovery for many years and were learning to accept themselves despite the uncertainty of further recovery. They were accepting of what they have but hopeful for further recovery. It is very important that clinicians are aware that patients move through an adaptive process and can assist with transitioning through it.

In this study adaptation following a hand nerve disorder was observed as a social process involving the individual, the family and wider social networks. This has not been explored in any depth in the qualitative literature relating to hand nerve disorders. 
Schier and Chan explored how acute hand injuries can affect patients in their roles as spouse, caregiver, and/or worker. ${ }^{32}$ They concluded that a hand injury has a profound impact on roles and relationships which concurs with our findings. The originality of our study is that it builds on these findings by suggesting that adaptation also occurs through relationships with others and this further impacts on the individual and can assist them to adapt.

\section{5:1 Limitations}

This study has some limitations. The chief investigator (first author) is an occupational therapist with clinical experience of treating hand nerve conditions and could have potentially had preconceived ideas about the main concepts. The choice of the constructivist grounded theory approach, however, acknowledges and values the researchers experience and interpretation of the data.

Only three participants chose to use visual methods, and one person did not provide copies for publication. While participants may not have understood the aims of using photography it could also be that the central concepts that the study identified related to adaptation and the psychological impact of the disorder. Neither concept lends itself well to being captured by photography and cannot be observed directly. 
Although it may be expected for nerve trauma to have a more life-changing effect, where compression is often deemed a transient condition that is treatable, this was not reflected in the data. An explanation for this could be that patients were recruited from a hand therapy department where it is common for only those with complex compressive disorders to be were referred for treatment. This needs to be considered when interpreting the results.

Lastly, using the ICF could be viewed as hindering the generation of codes from the data and instead forcing codes into predetermined categories. To safeguard against this several steps were taken to ensure the trustworthiness of the research.

\section{5:2 Trustworthiness}

In qualitative research, quality can be judged in terms of 'trustworthiness' and can be assessed using four criteria: confirmability, dependability, credibility and transferability ${ }^{33}$. Confirmability refers to the degree to which the results can be confirmed. In this study, an interview schedule/topic guide was developed to ensure comprehensiveness and avoid using leading questions, and a reflexive diary was kept. Data collection and analysis were conducted in a systematic manner until saturation occurred, evidencing that data interpretations were grounded in actual patient data and verbatim extracts were also used throughout. 
Grounded theory methodology was carefully chosen to explore the impact of hand nerve disorders from the patient's perspective and to generate an explanatory theory. The second author read all the interview transcripts independently and coded a random sample. This provides evidence that the study has been carefully conducted and that results are dependable.

The credibility criteria involve establishing that the results are credible or believable from the participants' perspective. This was provided by validation of the main concepts derived from the analysis by eleven participants from the original sample.

To enhance transferability, a thorough description of the research context and the assumptions that were central to the research was provided. This allows those in other contexts and settings to determine how transferable the study findings are for them. Participants were purposely sampled, ensuring maximum variation in diagnosis as well as sociodemographic factors such as age, sex and occupation. The constructed grounded theory was contextualised in a greater narrative on adaptation, and the wider clinical implications of the research findings are presented.

\section{5:3 Clinical implications}

The originality of this study is in using the ICF to guide the analysis of the interviews. This provided a unique opportunity to understand phenomena from the perspective of the participants, capturing inner thought processes as well as contextual influences ${ }^{1}$. 
This research is significant in highlighting that long term outcomes for people with hand nerve disorders were subject to many influences besides surgery or rehabilitation. This included coping strategies, patients' level of self-esteem, importance attached to appearance and social supports. This study illustrates that contextual factors play a very central role for people learning to adapt following a hand nerve condition.

These findings have important clinical implications such as the need for psychological screening and monitoring for patients with both acute and chronic nerve disorders. Consideration should also be given to providing dedicated therapy time for patients to learn how to change handedness as well as the provision of opportunities for recreational and vocational rehabilitation. The importance of the relationship with significant others for the patients during the adaptation process could signal a need for family members to be invited to attend therapy with the patient. Clinicians should acknowledge that they too are in relationship with their patients and need to adapt the information and advice provided to patients taking into account their individual circumstances and requirements.

$6 \quad$ Conclusions

This study provides valuable insights into the impact and the process of adaptation for people living with peripheral nerve disorders affecting the hand. It provides an explanatory theory of the social processes involved as patients experience nerve 
recovery. This should enable hand therapists to better support these patients as they navigate through this process.

6:1 Key findings

1. There is a need for ongoing psychological screening and support for patients with a peripheral nerve disorder and this should not be limited to those with traumatic injuries.

2. Learning to change handedness either temporarily or permanently was a challenge and a significant barrier to participating in recreational activities or work.

3. The impact of a hand nerve disorder forms part of a wider narrative on the process of adaptation.

4. Adaptation following a peripheral nerve disorder is a social process involving the individual, the family and wider social networks.

Acknowledgements:

I would like to give a special thank you to the Hand Therapy Department at the XXXX Hospital who assisted with patient identification and data collection. 
References

1. WHO. International Classification of Functioning, Disability and Health: ICF. Geneva: World Health Organization2001.

2. Mason J. Qualitative researching: Sage; 2002.

3. Sandelowski M. Using qualitative research. Qualitative Health Research. 2004;14:1366-1386.

4. Mays N, Pope C. Assessing quality in qualitative research. British Medical Journal. 2000;320:50-52.

5. Martin H. Patients' health beliefs and adaptation to carpal tunnel syndrome based on duration of symptomatic presentation. Journal of Hand Therapy. 2007;20:2935; quiz 36.

6. Jerosch-Herold C, Mason R, Chojnowski AJ. A qualitative study of the experiences and expectations of surgery in patients with carpal tunnel syndrome. Journal of Hand Therapy. 2008;21:54-61; quiz 62.

7. Khu KJ, Bernstein M, Midha R. Patients' perceptions of carpal tunnel and ulnar nerve decompression surgery. Canadian Journal of Neurological Sciences. 2011;38:268-273.

8. Chemnitz A, Dahlin LB, Carlsson IK. Consequences and adaptation in daily life patients' experiences three decades after a nerve injury sustained in adolescence. BMC Musculoskeletal Disorders. 2013;14:1-9.

9. Rosberg H, Carlsson K, Höjgård S, Lindgren B, Lundborg G, Dahlin L. Injury to the human median and ulnar nerves in the forearm - analysis of costs for treatment and rehabilitation of 69 patients in southern Sweden. Journal of Hand Surgery (British and European Volume). 2005;30:35-39.

10. Charmaz K. Constructing grounded theory: a practical guide through qualitative analysis Introducing Qualitative Methods Series. 2006.

11. Glaser BG, Strauss A. L.(1967). The discovery of grounded theory: strategies for qualitative research: Chicago: Aldine; 1967.

12. Charmaz K. 'Discovering'chronic illness: Using grounded theory. Social science \& medicine. 1990;30:1161-1172.

13. Strauss A, Corbin J. Discovery of grounded theory: Aldine; 1967.

14. Charmaz K. Grounded theory: methodology and theory construction International encyclopedia of the social \& behavioral sciences (Second Edition). Oxford: Elsevier; 2015:402-407.

15. Charmaz K. Grounded theory as an emergent method. Handbook of Emergent Methods. 2008:155-170.

16. Coyne IT. Sampling in qualitative research. Purposeful and theoretical sampling; merging or clear boundaries? Journal of Advanced Nursing. 1997;26:623-630.

17. Lasch KE, Marquis $P$, Vigneux $M$, et al. PRO development: rigorous qualitative research as the crucial foundation. Quality of Life Research. 2010;19:1087-1096.

18. Clark-Ibanez M. Framing the social world with photo-elicitation interviews. American Behavioral Scientist. 2004;47:1507-1527.

19. Drew SE, Duncan RE, Sawyer SM. Visual storytelling: a beneficial but challenging method for health research with young people. Qualitative Health Research. 2010;20:1677-1688.

20. Guillemin M, Drew S. Questions of process in participant-generated visual methodologies. Visual Studies. 2010;25:175-188. 
21. Charmaz K. Constructing grounded theory: Sage; 2014.

22. Rosén B, Jerosch-Herold C. Rehabilitation after Nerve Surgery. In: Dahlin L, ed. Current Treatment of Nerve Injuries and Disorders, Federation of European Societies for Surgery of the Hand Instructional Textbook: Palme Publications; 2014:344-358.

23. Charmaz K. Shifting the grounds: grounded theory in the 21st century. JM Morse et al.(2009). Developing grounded theory: the second generation: Sage; 2009:125-140.

24. Van der Kolk BA. The assessment and treatment of complex PTSD. Treating Trauma Survivors with PTSD2002:127-156.

25. Milton J. Comus: A Mask Presented at Ludlow Castle, 1634, Before the Earl of Bridgewater: W. Bristow; 1798.

26. Yancosek KE, Calderhead WJ. Efficacy of Handwriting for Heroes, a novel hand dominance transfer intervention. Hand Therapy. 2012;17:15-24.

27. Schkade JK, Schultz S. Occupational adaptation: toward a holistic approach for contemporary practice, part 1. American Journal of Occupational Therapy. 1992;46:829-837.

28. Bontje $\mathrm{P}$, Kinébanian A, Josephsson S, Tamura Y. Occupational adaptation: the experiences of older persons with physical disabilities. American Journal of Occupational Therapy. 2004;58:140-149.

29. Charmaz K. The body, identity, and self. The Sociological Quarterly. 1995;36:657680.

30. Hannah SD. Psychosocial issues after a traumatic hand injury: facilitating adjustment. Journal of Hand Therapy. 2011;24:95-103.

31. Bates E, Mason R. Coping strategies used by people with a major hand injury: a review of the literature. The British Journal of Occupational Therapy. 2014;77:289295.

32. Schier JS, Chan J. Changes in life roles after hand injury. Journal of Hand Therapy. 2007;20:57-69.

33. Lincoln Y, Guba E. Naturalistic inquiry. 1985, Beverly Hills: CA: Sage; 1999. 